\title{
Influence of Magnetic Field on Corrosion Behavior of Pure Aluminum in 3.5 wt. \% NaCl Solution
}

\author{
Xin Zhang ${ }^{1,2^{*}}$, Zehua Wang ${ }^{1}$, Zehua Zhou ${ }^{1}$, Guangheng Yang ${ }^{1}$, Jing Cao $^{1}$, Xin Cai ${ }^{1 *}$ \\ College of Mechanics and Materials, Hohai University, Nanjing, 210098, China \\ Nantong Ocean and Offshore Engineering Research Institute, Hohai University, Nantong, 226300, \\ China \\ *E-mail: zhangxin.007@ 163.com (X. Zhang) and xcai@hhu.edu.cn (X. Cai)
}

doi: $10.20964 / 2020.06 .46$

Received: 9 February 2020 / Accepted: 22 March 2020 / Published: 10 May 2020

\begin{abstract}
The effects of magnetic field on the corrosion behavior of pure aluminum and the properties of 3.5 wt. $\% \mathrm{NaCl}$ solution were investigated by electrochemical measurement, $\mathrm{pH}$ and conductivity tests. The effects of the change of the solution properties and the magnetic field on corrosion behavior of pure aluminum were discussed. The results indicated that the corrosion sensibility and corrosion rate of pure aluminum in 3.5 wt.\% NaCl solution were reduced by the magnetic field. However, magnetic field treatment could also increase $\mathrm{pH}$ and conductivity of $\mathrm{NaCl}$ solution. The change of solution properties induced by magnetic field caused the corrosion rate of pure aluminum to increase. After the magnetic field treatment was completed, the solution properties gradually recovered while the pure aluminum's corrosion rate decreased. During the corrosion process of pure aluminum, the inhibiting effect of magnetic field on the corrosion process was stronger than the promotion effect of the solution property change induced by magnetic field.
\end{abstract}

Keywords: magnetic field, corrosion behavior, magnetohydrodynamic theory, magnetization effect, magnetic memory effect

\section{FULL TEXT}

(C) 2020 The Authors. Published by ESG (www.electrochemsci.org). This article is an open access article distributed under the terms and conditions of the Creative Commons Attribution license (http://creativecommons.org/licenses/by/4.0/). 